\title{
Should patients reach certain knee function benchmarks before anterior cruciate ligament reconstruction? Does intense prehabilitation before anterior cruciate ligament reconstruction influence outcome and return to sports?
}

Martin Hägglund, Markus Waldén and R. Thomee

The self-archived postprint version of this journal article is available at Linköping University Institutional Repository (DiVA):

http:/ / urn.kb.se/ resolve?urn=urn:nbn:se:liu:diva- 124141

N.B.: When citing this work, cite the original publication.

Hägglund, M., Waldén, M., Thomee, R., (2015), Editorial Material: Should patients reach certain knee function benchmarks before anterior cruciate ligament reconstruction? Does intense prehabilitation before anterior cruciate ligament reconstruction influence outcome and return to sports? in BRITISH J OURNAL OF SPORTS MEDICINE, vol 49, issue 22, pp 1423-1424, British J ournal of Sports Medicine, 49(22), 1423-1424. https:/ / doi.org/ 10.1136/ bjsports-2015-094791

Original publication available at:

https:/ / doi.org/ 10.1136/ bjsports-2015-094791

Copyright: BMJ Publishing Group

http:// group.bmj.com/ 


\title{
Should patients reach certain knee function benchmarks before $A C L$ reconstruction? Does intense 'prehabilitation' before ACL reconstruction influence outcome and return to play?
}

\author{
Hägglund $M,{ }^{1}$ Waldén $M,{ }^{2}$ Thomeé $R \cdot{ }^{3}$ \\ ${ }^{1}$ Linköping University, Department of Medical and Health Sciences, Division of Physiotherapy \\ ${ }^{2}$ Linköping University, Department of Medical and Health Sciences, Division of Community Medicine \\ ${ }^{3}$ Gothenburg University, Institute of Neuroscience and Physiology, Department of Health and \\ Rehabilitation, Unit of Physiotherapy.
}

Recovery after $A C L$ reconstruction remains imperfect as shown by mediocre return to play results in recent systematic reviews.(1) In the March 2015 BJSM, Grindem and colleagues (2) asked whether intense preoperative rehabilitation could improve outcome after $\mathrm{ACL}$ reconstruction. They compared pre- and 2-year postoperative patient-reported knee function in two different cohorts of patients undergoing primary unilateral $\mathrm{ACL}$ reconstruction. One cohort included patients who underwent rehabilitation at a sports medicine clinic, "rehabilitation cohort", and the other cohort consisted of patients in the Norwegian national registry, representing "usual care". Patients in both cohorts were considered similar with respect to sex, age, time to surgery, graft, and prevalence of concomitant injuries.

In the rehabilitation cohort, patients underwent an intense 5-week preoperative rehabilitation programme, with the aim to regain at least $90 \%$ hamstring and quadriceps strength (as measured isokinetically in a seated position) and $90 \%$ hop performance, prior to surgery. $\mathrm{ACL}$ reconstruction was performed at one of seven different hospitals. The postoperative rehabilitation was individually tailored, again with the aim to regain $90 \%$ muscle strength and hop performance, and to return to sport.

\section{Superior results with a comprehensive rehabilitation programme}

Patients in the rehabilitation cohort reported significantly better Knee Injury and Osteoarthritis Outcome Score (KOOS) in all five subscales preoperatively compared with the usual care cohort, with differences up to 24.6 points in the various subscales ( 10 points considered a clinically relevant 
difference). Patients receiving usual care reported preoperative KOOS scores of 45.2, and 36.0 for the most patient-relevant subscales Sports and Quality of life, which tallies with e.g. the Swedish National Knee Ligament Register.(3)

Importantly, the superior knee function in the rehabilitation cohort remained at the 2-year follow-up in both KOOS Sports (85.1 vs. 67.6) and Quality of life (78.6 vs. 67.7). It was therefore suggested that patients can achieve better pre- and postoperative knee function with comprehensive preoperative rehabilitation, and it was concluded that "there is untapped potential for improving knee function prior to $\mathrm{ACL}$ reconstruction in the standard practice in Norway".(2)

\section{Should patients reach certain knee function benchmarks before ACL reconstruction?}

Is there further support in the literature for comprehensive preoperative rehabilitation ('or 'prehabilitation' as it is sometimes called)? In their systematic review, de Valk and colleagues (4) concluded that there is level III evidence (based on two cohort studies) that preoperative quadriceps strength deficits greater than $20 \%$, and low eccentric quadriceps torques, are associated with lower Cincinnati Knee score, poorer quadriceps strength, and lower KOOS Quality of life scores, respectively. In addition, a recent RCT showed that patients undergoing a 6-week rehabilitation programme prior to $\mathrm{ACL}$ reconstruction had superior hop performance and self-reported knee function 12 weeks postoperatively, compared with a control group who received no prehabilitation.(5)

A question that remains unanswered is what level of knee function is optimal (or needed) before undergoing ACL reconstruction? Interestingly, Grindem et al. (2) recommended that patients should have a leg symmetry index of $90 \%$ for muscle strength and hop ability prior to ACL reconstruction, which is similar to previous recommendations before returning to non-contact and non-pivoting sports after ACL reconstruction.(6) This may not be achievable for all ACL-deficient patients, however, and future studies should explore whether certain criteria should be met prior to $\mathrm{ACL}$ reconstruction to achieve superior functional postoperative outcomes, and to facilitate return to play.

\section{Is centralisation to specialised clinics needed in the future?}

To put the positive results from Grindem et al. (2) in perspective, we can compare the findings with those of the KANON trial by Richard Frobell and colleagues in the neighboring country, Sweden.(7) In that study, the corresponding 1-year postoperative KOOS scores in the subgroup of patients who started with "state-of-the-art" ACL rehabilitation alone, but ended up with a delayed ACL reconstruction, were 68.5 for Sports and 65.5 for Quality of life, respectively. Similar results were 
observed for patients receiving rehabilitation and early (within 10 weeks) ACL reconstruction, with 2year postoperative KOOS scores of 71.8 and 67.3 , respectively. Thus, these KOOS scores in the KANON trial are very similar to those of the usual care cohort, and the question is; what is the secret to the outstanding 2-year KOOS scores in the rehabilitation cohort at the Norwegian Research Center for Active Rehabilitation?

The superior results observed in the rehabilitation cohort may be attributed to factors other than the specific rehabilitation programme. We speculate that treatment at a specialised sports medicine clinic provides additional advantages beyond the rehabilitation programme alone -- quality education, attention to psychological responses during rehabilitation, supervised goal-oriented rehabilitation, etc.(8) Moreover, patient selection, with e.g. more motivated patients in the rehabilitation cohort, cannot be ruled out. Nonetheless, the novel approach taken by the authors in comparing outcomes from their prospective cohort study with that of the Norwegian national registry, representing usual care, is commended. Regardless of which parts of their treatment strategy was effective, the results suggest that pre- and postoperative care of patients undergoing $A C L$ reconstruction should be reserved for specialised clinics to achieve the best possible outcome for the patients.

\section{References}

1. Ardern CL, Taylor NF, Feller JA, et al. Fifty-five per cent return to competitive sport following anterior cruciate ligament reconstruction surgery: an updated systematic review and metaanalysis including aspects of physical functioning and contextual factors. Br J Sports Med. 2014;48:1543-52.

2. Grindem H, Granan LP, Risberg MA, et al. How does a combined preoperative and postoperative rehabilitation programme influence the outcome of $A C L$ reconstruction two years after surgery? A comparison between patients in the Delaware-Oslo ACL Cohort and the Norwegian National Knee Ligament Registry. Br J Sports Med 2015;49:385-9.

3. Kvist J, Kartus J, Karlsson J, et al. Results from the Swedish National Anterior Cruciate Ligament Register. Arthroscopy 2013;30:803-810.

4. de Valk EJ, Moen MH, Winters M, et al. Preoperative patient and injury factors of successful rehabilitation after anterior cruciate ligament reconstruction with single-bundle techniques. Arthroscopy 2013;29:1879-95.

5. Sharaanin SR, O'Hare C, Quinn A, et al. Effect of prehabilitation on the outcome of anterior cruciate ligament reconstruction. Am J Sports Med 2013;41:2117-27. 
6. Thomeè R, Kaplan $\mathrm{Y}, \mathrm{Kvist} \mathrm{J}$, et al. Muscle strength and hop performance criteria prior to return to sports after ACL reconstruction. Knee Surg Sports Traumatol Arthrosc 2011;19:1798-1805.

7. Frobell RB, Roos EM, Roos HP, et al. A randomized trial of treatment for acute anterior cruciate ligament tears. N Engl J Med 2010;363:331-42.

8. Czuppon S, Racette BA, Klein SE, et al. Variables associated with return to sport following anterior cruciate ligament reconstruction: a systematic review. Br J Sports Med. 2014;48:356-64. 